\title{
АНАЛИЗ ГЛУБИННЫХ \\ СЕМАНТИЧЕСКИХ СТРУКТУР КАК СПОСОБ ОПЕРАЦИОНАЛИЗАЦИИ ПРОЦЕССУАЛЬНОЙ МОДЕЛИ СТРУКТУРЫ ОБРАЗА МИРА
}

\section{Склейнис В.A.}

Цель. Статья посвящена проблеме операчионализации процессуальной модели структуры образа мира. Предметом анализа выступают модели систем значений. Автор ставит изелью сопоставить процессуальную модель структуры образа мира с моделями систем значений, описьвающих жизненный сценарий личности, а также архетипические структуры.

Метод или методология проведения работы. В качестве метода исследования нами был использован сопоставительный анализ компонентов процессуальной модели структуры образа мира с одной стороны и многоуровневых семантических структур с другой.

Результаты. Результаты работы заключаются в том, что автор рассматривает процессы развёртывания сиенарных и архетипических структур как частный случай динамики прочессуальной модели. С позиции уровня функционирования процесс из развёртывания может быть рассмотрен как влияние мотивационной подсистемы на ичелевую и функциональную, в то время как с позиции уровня обобщения - как процесс смыслообразования, характеризующийся переходом от синкретической и комплексной подсистем к понятийной. Данный процесс может осуществляться в нескольких направлениях функиионирования: уровню внутренней деятельности соответствуют прочессы внутриличностной динамики смысловых структур; уровню коммуникативной деятельности - процессы межличностного взаимодействия, а также взаимодействие субъекта с культурой как полем коллективных смыслов. Уровню 
практической деятельности можно поставить в соответствие поведенческие акты, обусловленные влиянием архетипических моделей и сиенарных паттернов.

Область применения результатов. Решение задачи сопоставления моделей систем значений позволяют достичь эффекта синергии, с одной стороны позволяя дополнить представления о глубинных структурах образа мира, а с другой-использовать инструментарий психологии субъективной семантики и психосемантики для анализа процессов реализащии жизненного сценария личности и архетипа. Полученные данные могут быть использованы для моделирования прочессов реализащии глубинных структур средствами психологии субъективной семантики при конструировании сообщения.

Ключевые слова: образ мира; прочессуальная модель; семантические структуры; системы значений; жизненный сценарий личности; архетип.

\section{ANALYSIS OF DEEP SEMANTIC STRUCTURES AS A METHOD OF OPERATIONALIZATION OF THE PROCESSUAL MODEL OF THE STRUCTURE OF AN IMAGE OF THE WORLD}

\section{Skleynis V.A.}

Purpose. The article is devoted to the problem of operationalization of the processual model of the structure of an image of the world. The subject of the analysis is models of the meaning systems. The author aims to compare the process model of the structure of an image of the world with the models of the systems of meanings like the life script or archetypal structures.

Methodology. As a research method, we used a comparative analysis of the components of the processual model of the structure of an image of the world on the one hand and multi-level semantic structures on the other.

Results. The results of the study are that the author considers the processes of deployment of the life script and archetypal structures as a 
special case of the dynamics of the processual model. From the point of view of the level of functioning, the process of their unfolding can be considered as the influence of the motivational subsystem on the target and functional, while from the point of view of the level of generalization-as the process of meaning formation, characterized by the transition from syncretic and complex subsystems to the conceptual one. This process can be carried out in several directions of functioning: the level of internal activity corresponds to the processes of intrapersonal dynamics of semantic structures; the level of communicative activity-the processes of interpersonal interaction, as well as the interaction of the subject with culture as a field of collective meanings. The level of practical activity can be correlated with behavioral acts caused by the influence of archetypal models and scenario patterns.

Practical implications. Solving the problem of comparing models of the systems of meanings allows us to achieve a synergy effect, on the one hand, allowing us to supplement the ideas about the deep structures of an image of the world, and on the other - to use the tools of the psychology of subjective semantics and psychosemantics to analyze the processes of implementing the life script and the archetype. The obtained data can be used to model the processes of implementing deep structures by means of the psychology of subjective semantics in the construction of a message.

Keywords: image of the world; processual model; semantic structures; systems of meanings; life script; archetype.

\section{Введение}

Процессуальная модель структуры образа мира является одной из самых детализированных моделей систем значений, позволяющей не только осуществить рассмотрение образа мира с различных ракурсов, но и_описать соотношения между его подсистемами, выделяемыми исходя из различных оснований. Вместе с тем, остаётся неразработанным вопрос создания методического инструментария для эмпирических исследований, основанных на данной модели. В то же время, в работах, посвящённых многоуровневым семантическим образованиям, таким, как архетипы или жизненный сценарий 
личности осуществляется эмпирическое описание взаимодействия разноуровневых семантических структур. Моделирование глубинных семантических структур используется в различных сферах коммуникативной практики: в искусстве [24], сфере политической [27] и PR коммуникации [25]. Описание данных образований в рамках процессуальной модели образа мира позволит использовать накопленные эмпирические данные для осуществления её операционализации, что, в свою очередь, позволит объединить подходы к организации коммуникативных практик, основанные на моделировании глубинных семантических структур и психологии субъективной семантики.

\section{Материалы и методы}

В качестве метода исследования нами был использован сопоставительный анализ. компонентов процессуальной модели структуры образа мира с одной стороны и многоуровневых семантических структур с другой. Основанием для сопоставления семантических структур, описываемых в различных моделях, послужило сходство их проявлений: компоненты моделей, описывающие идентичные явления, поставлены в соответствие друг другу.

\section{Дискуссия}

В рамках процессуальной модели структуры образа мира, предложенной В.П. Серкиным, образ мира рассматривается как интегральная система значений субъекта. Исходя из понимания образа мира как иерархизированной системы, представленной совокупностью значений, представленных множеством форм, В.П. Серкин в качестве одной из надсистем, в которых функционирует образ мира рассматривает образ жизни - систему деятельностей, в которую включён субъект. Исходя из концепций макроструктуры деятельности А.Н. Леонтьева и системно-структурного строения мыследеятельности Г.П. Щедровицкого, в структуре образа жизни как системы деятельностей человека, иерархизированных мотивацией, выделяется три уровня активности: уровень внутренней деятель- 
ности, уровень коммуникативной деятельности и уровень практической деятельности.

Представленные уровни образа жизни различаются между собой формой презентации временного континуума. На уровне внутренней деятельности представления о пространстве и времени определяются субъективностью и могут в значительной степени варьироваться психической деятельностью. Так, в плане внутренней деятельности возможно представление удалённых в пространстве и времени объектов. Кроме того, сами пространственные и временные характеристики картины мира могут претерпевать трансформации под влиянием семантических структур [10]. На уровне коммуникативной деятельности время является конвенциональным, поскольку для коммуникации с другим человеком необходимо синхронизировать с ним время и место коммуникативного акта. Наконец, на уровне практической деятельности для реализации действий человеку необходимо соотнести тело и инструментарий со свойствами предметной действительности.

Говоря об образе жизни как о детерминанте образа мира, важно акцентировать внимание на взаимообратном характере данной детерминации, поскольку система значений субъекта является не только продуктом системы деятельностей, но и фактором, способным оказывать влияние на содержание деятельности. Исходя из данного положения, мы можем говорить о том, что для наиболее полного и комплексного рассмотрения системы значений необходимо рассмотрение её в единстве и системой деятельностей, находящейся в отношениях взаимной детерминации с образом мира.

Подобным образом образ мира рассматривается в рамках процессуальной модели. Рассматривая образ мира как систему значений, В.П. Серкин отмечает, что характер связей между элементами данной системы является не логическим, а мотивационно-целевым. Основываясь на данном тезисе, автор выделяет три подсистемы, соответствующие уровням деятельности, выделяемым в концепции А.Н. Леонтьева.

Подсистема уровня деятельности включает в себя мотивационный слой системы значений и представляет собой совокупность первич- 
ных мотивационных образований, лежащих в основе образа мира. Подсистема уровня действий представляет собой целевой слой системы значений. Содержанием данного слоя являются представления о существующем положении вещей. Основной формой значений на данном уровне являются предметные значения - формы значений, отражающие характеристики объекта исходя из его предназначения. Подсистема уровня операций представляет собой ситуационный слой системы значений; основными формами презентации значения на данном уровне являются модальные образы и ощущения, презентующиеся в системах сенсорных эталонов и перцептивных операций.

Описывая модель образа мира как процесса, В.П. Серкин выделяет три критерия для разделения данной модели на подсистемы. По уровням функционирования форм значений в деятельности автор выделяет мотивационную, целевую и ситуационную подсистемы. Согласно критерию уровня обобщения - синкретическую, комплексную и понятийную подсистемы. По уровням образов жизни как систем реализуемых деятельностей в структуре образа мира выделяются план внутренней деятельности, план коммуникативной деятельности и план практической деятельности.

Соотношение подсистем образа мира рассматривается исходя из многомерной квазипространственной модели. Мотивационная подсистема пронизывает целевую и ситуационную, в то время как уровни обобщения рассматриваются в качестве функциональных состояний каждой из подсистем, сменяющихся в процессе развития системы, а планы деятельности - как направления функционирования. Рассматривая функциональную структуру образа мира, В.П. Серкин [16] относит к его функциям иерархизацию деятельностей, хранение интегральной системы значений, предварительную и оперативную генерацию предметных гипотез, функционирование значений в деятельности, саморазвитие образа мира, а также функцию рефлексии.

Таким образом, использование процессуальной модели систем значений, позволяет рассматривать комплексно рассматривать образ мира субъекта с учетом множества аспектов, при этом изучая его в неразрывном единстве с деятельностью. 
Перспектива комплексного исследования образа мира ставит перед нами задачу операционализации процессуальной модели и подбора батареи методик, позволяющей охватить различные аспекты функционирования образа мира. Решение данной задачи с использованием процессуальной модели может быть осуществлено посредством объединения подходов, рассматривающих различные аспекты функционирования семантических структур.

Поскольку функционирование системы значений на каждом из уровней представляет собой процесс взаимодействия со средой, детерминированный как внутренними, так и внешними факторами, в наших работах $[19,20]$ уровням функционирования образа мира поставлены в соответствие процессы нелинейной динамики семантических структур. Сопоставляя модели нелинейной динамики смысловых образований, предложенные Г.В. Паршиковой и Л.В. Бронник с одной стороны и направления функционирования образа мира в процессуальной модели с другой, мы можем поставить в соответствие уровню внутренней деятельности процессы функционирования сознания [12], в то время как уровню коммуникативной деятельности соответствуют процессы формирования концепта, детерминированные внешним дискурсом с одной стороны и когнитивными структурами с другой [4]. При этом семантические структуры, представленные на каждом из уровней, рассматриваются нами как продукт нелинейной детерминации, объединяющей внутренние и внешние воздействия. Наконец, рассматривая по аналогии с вышеуказанными уровень практической деятельности как интегральный продукт внутренней и внешней детерминации, мы можем поставить ему в соответствие соединение в операциональной стороне деятельности индивидуального стиля [22] и условий её протекания.

Характеризуя взаимодействие структур образа мира, следует отметить, что значения, характеризующиеся различным уровнем обобщения, могут взаимодействовать между собой. Так, например, синкретические значения могут оказывать влияние на формирование «понятийных». На наш взгляд, психоаналитические концепции, описывающие влияние структур, сформированных на ранних этапах 
онтогенеза, можно рассматривать в рамках процессуальной модели как взаимодействие форм значений, различающихся по уровню обобщения. Нелогичность, иррациональность проявлений данных структур обусловлена иной «логикой построения», присущей синкретическим формам значений.

В наших работах $[20,21]$ жизненный сценарий личности рассматривается как компонент глубинных структур образа мира, а процесс его реализации - как проецирование на нижележащие структуры, проявляющиеся в процессах смыслообразования. При этом сам жизненный сценарий, формирующийся, согласно Э. Бёрну [28] в период, соответствующий комплексной стадии развития значений [6], в то время как в процессе его реализации происходит формирование значений, существующих в понятийной форме.

В свою очередь, синкретическим формам значения, проявляющимся на нижележащих уровнях в понятийной форме, можно поставить в соответствие архетипические структуры. Так, Ю.М. Перевозкина выделяет в структуре архетипического пространства уровень недифференцированного пространства, характеризующийся синкретизмом и иррациональностью, структуры которого проявляются на уровнях мифологического и информационного пространства в конкретных образах.

Наконец, описывая взаимодействие подсистем, соответствующих уровням деятельности, В.П. Серкин указывает на то, что мотивационная подсистема пронизывает целевую и функциональную подобно тому, как нервная система пронизывает ткани организма. При этом величина мотивации определяет область апперцептивности, детерминируя направленность внимания и представленность в сознании фрагментов образа мира. Описывая механизмы проявления жизненных сценариев $[8,10]$ и архетипов [7, 8, 23], авторы указывают тот факт, что глубинные структуры оказывают динамическое и эмоциональное влияние на нижележащие структуры. Следовательно, процессы реализации глубинных структур можно рассматривать как частный случай проявления мотивационной подсистемы образа мира в целевой и операциональной. 


\section{Заключение}

Таким образом, сопоставляя процессуальную модель структуры образа мира с одной стороны и процессы динамики многоуровневых семантиче6ских структур с другой, мы можем рассматривать процессы развёртывания сценарных и архетипических структур как частный случай динамики процессуальной модели. С позиции уровня функционирования процесс из развёртывания может быть рассмотрен как влияние мотивационной подсистемы на целевую и функциональную, в то время как с позиции уровня обобщения как процесс смыслообразования, характеризующийся переходом от синкретической и комплексной подсистем к понятийной. Данный процесс может осуществляться в нескольких направлениях функционирования: уровню внутренней деятельности соответствуют процессы внутриличностной динамики смысловых структур; уровню коммуникативной деятельности - процессы межличностного взаимодействия, а также взаимодействие субъекта с культурой как полем коллективных смыслов. Уровню практической деятельности можно поставить в соответствие поведенческие акты, обусловленные влиянием архетипических моделей и сценарных паттернов.

Рассматривая процессы проявления архетипических и сценарных структур на нижележащих уровнях как частный случай перехода от синкретической и комплексной систем к понятийной, мы можем экстраполировать на процессуальную модель методики, предназначенные для их изучения. Так, для исследования глубинных структур синкретической и комплексной подсистем, нам представляется целесообразным использование таких методик, как, например, метафорические ассоциативные карты [7] или опросник С.П. Лукьяновой [11], в то время как для исследования их проявлений на уровне понятийной подсистемы могут быть использованы методы психологии субъективной семантики и психосемантики [17].

Исследование различных направлений функционирования образа мира может быть осуществлено посредством использования методик, направленных на изучение различных планов протекания деятельности. При этом уровню внутренней деятельности можно 
поставить в соответствие описанные выше методики, направленные на изучение внутриличностной динамики смысловых структур. Для исследования уровня коммуникативной деятельности нам представляется целесообразным использовать методики анализа текста, включённого в коммуникативное пространство, такие как, например, дискурс-анализ [2]. Для анализа уровня практической деятельности может быть использован метод наблюдения. Так, Н.В. Бондарчук [3] пишет о возможности использования наблюдения как дополнительного метода для интерпретации результатов психосемантических методик. Аналогичным образом данный метод может быть использован для анализа различных уровней функционирования значений в деятельности. Мотивационная и целевая подсистемы могут быть исследованы посредством методик изучения мотивации [6, 16] и целей деятельности [18] соответственно, в то время как для операциональной подсистемы может применяться методика наблюдения.

\section{Список литературы}

1. Агавелян О.К., Агавелян Р.О., Перевозкина Ю.М., Перевозкин С.Б., Рюмина Т.В. Особенности выраженности архетипов и эмоциональные характеристики личности // Мир науки, культуры, образования. 2012. № 5 (36). С. 39-42.

2. Богданова И.А., Звездакова И.В. Архетипический концепт и символ как синергетические структуры // Филологические науки. Вопросы теории и практики. 2015. № 3-3 (45). C. 33-35. https://www.gramota. net/materials/2/2015/3-3/8.html

3. Бондарчук Н.В. Психологическое содержание старательского труда // Организационная психология. 2013. T.3, №1. С. 78-94. https:// orgpsyjournal.hse.ru/2013-3-1/102764525.html

4. Бронник Л.В. Когнитивно-синергетический подход к языку: философско-методологический анализ: диссертация ... доктора философских наук: 09.00.08; [Место защиты: Юж. федер. ун-т]. Ростов-на-Дону, 2013. 348 с.

5. Выготский Л.С. Мышление и речь. М.: АСТ: Хранитель, 2008. 668 с. 
6. Зарубко Е.Ю. Психосемантика обобщенных категорий в межсубъектном взаимодействии: автореф. дис. ... канд. психол. наук. Тюмень, 2010. 26 с.

7. Капустина Т.В. Создание и апробация методики «Способ оценки личности - 12 Архетипов плюс» для диагностики индивидуальноличностных характеристик // Психология. Историко-критические обзоры и современные исследования. 2018. Т. 7. № 1А. С. 64-75. http://publishing-vak.ru/file/archive-psycology-2018-1/7-kapustina.pdf

8. Коршунова С.А. К проблеме эволюции архетипического сознания // Научный Вестник Воронежского государственного архитектурностроительного университета. 2015. № 1 (5). С. 61-65.

9. Котельникова Ю.А. Жизненный сценарий личности как системный конструкт её функционирования // Вестник СПбГУ. Социология. 2014. Вып. 4. С. 16-30.

10. Леонтьев, Д.А. Психология смысла: природа, строение и динамика смысловой реальности. 3-е изд., доп. М.: Смысл, 2007. 511 с.

11. Лукьянова С.П. Метод исследования жизненного сценария личности // Теоретическая и экспериментальная психология. 2011. Т. 4, №3. C. 55-61. http://www.tepjournal.ru/images/pdf/2011/3/07.pdf

12. Паршикова Г.В. Когнитивно-синергетический подход к осмыслению природы сознания. Дисс. канд. филос. наук. Брянск, БГТУ, 2015. 147 с.

13. Перевозкина Ю.М., Дмитриева Н.В., Перевозкин С.Б., Рюмина Т.В., Ганпанцурова О.Б. Построение конструкта для изучения доминантного архетипа // Сибирский педагогический журнал. 2013. № 3. C. 213-217. https://repo.nspu.ru/bitstream/nspu/1220/1/postroeniekonstrukta-dlya-izuch.pdf

14. Перевозкина Ю.М. Структурные трансформации психосемантических мифологических пространств личности: на примере славянской культуры: дисс ... канд. психол. наук. Новосибирск, 2009. $222 \mathrm{c}$.

15. Серкин В.П. Структура и функции образа мира в практической деятельности. Дисс. ... докт. психол. наук. М.: МГУ, 2005. 356 с.

16. Серкин В.П. Пять определений понятия «образ мира» // Вестник МГУ. Серия 14. Психология. 2006. №1. С. 11-19. 
17. Серкин В.П. Психосемантика: учебник и практикум для бакалавриата и магистратуры. М.: Юрайт, 2016. 318 с.

18. Сидоров, К.Р., Васильев И.А. Методика исследования содержания целей деятельности человека // Вестник Московского Государственного Университета. Серия 14. Психология. 2018. №3. С. 90-106. https://doi.org/10.11621/vsp.2018.03.90

19. Склейнис В.А. Сравнительный анализ семантических структур оценивания временного континуума // Интернет-журнал «Мир науки». 2016. Том 4, № 6. http://mir-nauki.com/PDF/72PSMN616.pdf

20. Склейнис В.А. Нелинейная динамика межличностных форм смысла // Психолог. 2018. № 2. С. 30-37. https://doi.org/10.25136/24098701.2018.2.24839

21.Склейнис В.А. Архетипические аспекты динамики смысловых структур // Психолог. 2019. № 2. С. 1-8. https://doi.org/10.25136/24098701.2019.2.28386

22. Шадриков В.Д. Психология деятельности человека. М.: ИПРАН, 2013. 464 c.

23. Benson J.E., Elder G.H. Jr. Young Adult Identities and Their Pathways: a Developmental and Life Course Model // Developmental Psychology, 2011, vol. 47, no. 6, pp. 1646-1657. https://doi.org/10.1037/a0023833

24. Chang, H. M., Ivonin, L., Díaz, M., Català, A., Chen, W., \& Rauterberg, M. From mythology to psychology: Identifying archetypal symbols in movies // Technoetic Arts, 2013, vol. 11, no. 2, pp. 99-113. https://doi. org/10.1386/tear.11.2.99_1

25. Du Toit, D. Archetypal values, career orientations, perceived career success and meaningfulness, University of South Africa. Pretoria, 2010. 214 p. http://uir.unisa.ac.za/handle/10500/4856

26. McPeek, R.W. The Pearson-Marr Archetype Indicator and Psychological Type // Journal of Psychological Type, 2008, vol. 68, no. 7, pp. 5367. https://www.researchgate.net/publication/216101940

27. Plakhtiy T. Archetypal model of emergence, escalation and resolution of social conflicts // Public management: collection, 2017, no. 3 (8), pp. 235-248. http://dx.doi.org/10.2139/ssrn.3007128

28. Stewart, I., Joines, S. TA Tomorrow // Transactional Analysis Journal. 2011, vol. 41, no. 3, pp. 221-229. https://doi.org/10.1177/036215371104100304 


\section{References}

1. Agavelyan O.K., Agavelyan R.O., Perevozkina Yu.M., Perevozkin S.B., Ryumina T.V. Mir nauki, kul'tury, obrazovaniya, 2012, no. 5 (36), pp. 39-42.

2. Bogdanova I.A., Zvezdakova I.V. Filologicheskie nauki. Voprosy teorii i praktiki, 2015, no. 3-3 (45), pp. 33-35. https://www.gramota.net/materials/2/2015/3-3/8.html

3. Bondarchuk N.V. Organizatsionnaya psikhologiya, 2013, vol. 3, no. 1, pp. 78-94. https://orgpsyjournal.hse.ru/2013-3-1/102764525.html

4. Bronnik L.V. Kognitivno-sinergeticheskiy podkhod kyazyku: filosofsko-metodologicheskiy analiz [Cognitive-synergetic approach to language: philosophical and methodological analysis]. Rostov-na-Donu, 2013, 348 p.

5. Vygotskiy L.S. Myshlenie i rech [Thinking and speaking]. M.: AST: Khranitel', 2008, 668 p.

6. Zarubko E.Yu. Psikhosemantika obobshchennykh kategoriy v mezhsub"ektnom vzaimodeystvii [Psychosemantics of generalized categories in intersubjective interaction]. Tyumen, 2010, $26 \mathrm{p}$.

7. Kapustina T.V. Psikhologiya. Istoriko-kriticheskie obzory i sovremennye issledovaniya, 2018, vol. 7, no. 1A, pp. 64-75. http://publishing-vak.ru/ file/archive-psycology-2018-1/7-kapustina.pdf

8. Korshunova S.A. Nauchnyy Vestnik Voronezhskogo gosudarstvennogo arkhitekturno-stroitel'nogo universiteta, 2015, no. 1 (5), pp. 61-65.

9. Kotelnikova Yu.A. Vestnik SPbGU. Sotsiologiya, 2014, no. 4, pp. 16-30.

10. Leontev D.A. Psikhologiya smysla: priroda, stroenie i dinamika smyslovoy real'nosti [Psychology of meaning: nature, structure and dynamics of meaningful reality]. M.: Smysl, 2007, 511 p.

11. Luk'yanova S.P. Teoreticheskaya i eksperimental'naya psikhologiya, 2011, vol. 4, no. 3, pp. 55-61. http://www.tepjournal.ru/images/pdf/2011/3/07.pdf

12.Parshikova G.V. Kognitivno-sinergeticheskiy podkhod k osmysleniyu prirody soznaniya [Cognitive-synergetic approach to understanding the nature of consciousness]. Bryansk, BGTU, 2015, 147 p.

13.Perevozkina Yu.M., Dmitrieva N.V., Perevozkin S.B., Ryumina T.V., Ganpantsurova O.B. Sibirskiy pedagogicheskiy zhurnal, 2013, no. 3, pp. 213-217. https://repo.nspu.ru/bitstream/nspu/1220/1/postroenie-konstrukta-dlya-izuch.pdf 
14. Perevozkina Yu.M. Strukturnye transformatsii psikhosemanticheskikh mifologicheskikh prostranstv lichnosti : na primere slavyanskoy kul'tu$r y$ [Structural transformations of psychosemantic mythological spaces of personality: on the example of Slavic culture]. Novosibirsk, 2009, 222 p.

15. Serkin V. P. Struktura i funktsii obraza mira v prakticheskoy deyatel'nosti [Structure and functions of the image of the world in practice]. M.: MGU, 2005, $356 \mathrm{p}$.

16. Serkin V.P. Vestnik MGU. Seriya 14. Psikhologiya, 2006, no. 1, pp. 11-19.

17. Serkin V.P. Psikhosemantika: uchebnik i praktikum dlya bakalavriata $i$ magistratury [Psychosemantics: textbook and workshop for undergraduate and graduate programs]. M.: Yurayt, 2016. 318 p.

18. Sidorov, K.R., Vasilev I.A. Vestnik Moskovskogo Gosudarstvennogo Universiteta. Seriya 14. Psikhologiya, 2018, no. 3, pp. 90-106. https:// doi.org/10.11621/vsp.2018.03.90

19. Skleynis V.A. Mir nauki, 2016, vol. 4, no. 6. http://mir-nauki.com/PDF/72PSMN616.pdf

20.Skleynis V.A. Psikholog, 2018, no. 2, pp. 30-37. https://doi. org/10.25136/2409-8701.2018.2.24839

21. Skleynis V.A. Psikholog, 2019, no. 2, pp. 1-8. https://doi.org/10.25136/24098701.2019.2.28386

22. Shadrikov V.D. Psikhologiya deyatel'nosti cheloveka [Psychology of human activity]. M.: IPRAN, 2013, 464 p.

23. Benson J. E., Elder G. H. Jr. Young Adult Identities and Their Pathways: a Developmental and Life Course Model. Developmental Psychology, 2011, vol. 47, no. 6, pp. 1646-1657. https://doi.org/10.1037/a0023833

24. Chang, H. M., Ivonin, L., Díaz, M., Català, A., Chen, W., \& Rauterberg, M. From mythology to psychology: Identifying archetypal symbols in movies. Technoetic Arts, 2013, vol. 11, no. 2, pp. 99-113. https://doi. org/10.1386/tear.11.2.99_1

25. Du Toit, D. Archetypal values, career orientations, perceived career success and meaningfulness, University of South Africa. Pretoria, 2010. 214 p. http://uir.unisa.ac.za/handle/10500/4856

26. McPeek, R.W. The Pearson-Marr Archetype Indicator and Psychological Type. Journal of Psychological Type, 2008, vol. 68, no. 7, pp. 53-67. https://www.researchgate.net/publication/216101940 
27. Plakhtiy T. Archetypal model of emergence, escalation and resolution of social conflicts. Public management: collection, 2017, no. 3 (8), pp. 235 248. http://dx.doi.org/10.2139/ssrn.3007128

28. Stewart, I., Joines, S. TA Tomorrow. Transactional Analysis Journal. 2011, vol. 41, no. 3, pp. 221-229. https://doi.org/10.1177/036215371104100304

\section{ДАННЫЕ ОБ АВТОРЕ}

Склейнис Виктор Александрович, доцент кафедры социальных и гуманитарных наук, кандидат психологических наук Северо-Восточный государственный университет ул. Портовая 13, г. Магадан, Магаданская область, 685000 , Российская Федерация kartiala@list.ru

\section{DATA ABOUT THE AUTHOR}

Skleynis Viktor A., Associate Professor, Department of Social Sciences and Humanities, PhD in Psychology North-Eastern State University 13, Portovaya St., Magadan, 685000, Russian Federation kartiala@list.ru SPIN-code: 4764-9822

ORCID: 0000-0002-6653-4924 ResearcherID: $A B H-3121-2020$ 